\title{
COLÉGIO ESTADUAL GOVERNADOR LUIZ VIANA FILHO (1956-1994): HISTÓRIA, ARQUIVO ESCOLAR E PRODUÇÃO DE CATÁLOGO DE FONTES
}

\author{
Maryana Gonçalves Souza \\ Universidade do Estado da Bahia (UNEB) - Campus VI- Caetité \\ maarii95@hotmail.com \\ Antonieta Miguel \\ Universidade do Estado da Bahia (UNEB) - Campus VI- Caetité \\ antonietamigue140@yahoo.com.br
}

\begin{abstract}
RESUMO
O presente texto é resultado do projeto Colégio Estadual Governador Luiz Viana Filho: instituição, arquivo escolar e possibilidades de pesquisa (1956-1994), com apoio financeiro do PICIN/UNEB que almeja conhecer, inventariar e catalogar os documentos da instituição e produzir um Catálogo de Fontes Primárias, apresentando a documentação pesquisada e suas possibilidades de pesquisa em História da Educação. Os documentos foram levantados e catalogados, realizando a análise do seu conteúdo e seu estado. Depois se realizou a produção escrita e gráfica do Catálogo. A pesquisa desenvolvida permitiu visualizar a potencialidade das instituições escolares e seus arquivos e a situação crítica deste local, necessitando descontruir a invisibilidade social perante os espaços escolares e seu patrimônio.
\end{abstract}

Palavras-chave: Colégio Luiz Viana. Arquivos escolares. Catálogo de Fontes Primárias.

\section{HIGH SCHOOL GOVERNOR LUIZ VIANA FILHO (1956-1994): HISTORY, SCHOOL FILE AND PRODUCTION OF CATALOG OF SOURCES}

\begin{abstract}
This text is the result of the High School project Governor Luiz Viana Filho: institution, school file and research possibilities (1956-1994), with financial support from Picin/UNEB wich want to understand, inventory and catalog the documents of the institution and produce a catalog of Original Sources, with their searched documentation and their research possibilities by History of Education. The documents were collected and cataloged, performing analysis of their content and their status. Then a written end graphical catalog was produced. The research developed allowed visualization of the potential of the academic institution and their records and the local critical situation, requiring deconstruction of the social presence invisibility in High School spaces and their heritage.
\end{abstract}

Keywords: High School Luiz Viana. School file. Catalog of Original Sources.

COLEGIO ESTADUAL GOVERNADOR LUIZ VIANA FILHO (1956-1994): HISTORIA, ARCHIVO ESCOLAR Y ELABORACIÓN DE UN CATALOGO DE FUENTES PRIMARIAS

\author{
RESUMEN
}


El texto es resultado del proyecto Colégio Estadual Governador Luiz Viana Filho: instituição, arquivo escolar e possibilidades de pesquisa (1956-1994), con el apoyo financiero de Picin/UNEB cuyo el objetivo es conocer, inventariar y catalogar los documentos de la institución y producir un catálogo de fuentes primarias, con la documentación investigado y sus posibilidades de investigación en Historia de la Educación. Los documentos fueron recogidos y catalogados, realizando el análisis de su contenido y su estado. Después se llevó a cabo de la escritura y la producción gráfica del catálogo. La investigación desarrollada permitió visualizar el potencial de las instituciones educativas y sus archivos y la situación crítica de este lugar, lo que requiere la deconstrucción de la invisibilidad social antes de los espacios escolares y su patrimonio.

Palabras clave: Colegio Luiz Viana. Archivos escolares. Catalogo de Fuentes Primarias.

\section{COLLEGE D'ÉTAT GOUVERNEUR LUIZ VIANA FILHO (1956-1994) : HISTOIRE, FICHIER SCOLAIRE ET PRODUCTION DU CATALOGUE DES SOURCES}

\section{RÉSUMÉ}

Le présent texte est le résultat du projet Collège d'État Gouverneur Luiz Viana Filho (19561994), avec le soutien financier du PICIN/UNEB que cherche à connaître, inventorier et cataloguer les documents de l'institution et produire un Catalogue des Sources Primaires, en présentant la documentation recherchée est ses possibilités de recherche sur l'Histoire de la Education. Les documents ont été collectés et catalogués, en réalisant l'analyse de leur contenu et de leur état. Ensuite, la production écrite et graphique du Catalogue a été réalisée. La recherche conçue a permis de visualiser la potentialité des institutions scolaires et ses fichiers et la situation critique de cet endroit, en ayant besoin de déconstruire l'invisibilitésociale devant les espaces scolaires et leur patrimoine.

Mots-clés: Collège Luiz Viana. Fichiers scolaires. Catalogue des Sources Primaires.

\section{INTRODUÇÃO}

Na segunda metade do século XX, o campo da História da Educação se configura em um novo cenário movido pelas incursões da renovação historiográfica, em especial através dos Annales, que possibilitou uma abertura deste campo histórico-educativo com a inserção de novas temáticas, fontes, metodologias, leituras, investigações, modalidades interpretativas, problematizações, novos olhares e objetos.

Dentro deste contexto de mudanças, junto à ascensão de uma nova tendência da produção historiográfica, as instituições escolares e de ensino ganharam no Brasil, a partir de 1990, grande visibilidade e interesse no campo de pesquisas da História da Educação. As transformações ocorridas permitiram que sua ótica de investigação se vinculasse a um pluralismo de conhecimentos e temas tendo em vista objetos singulares. Os estudos averiguaram o interior da instituição escolar, priorizando a sua cultura, o campo docente e 
discente, as disciplinas, materiais didáticos, práticas didáticas, uma vez que, nas décadas de 1970 e 1980, existiam poucas produções relacionadas às instituições escolares e ao seu interior que incorporavam a complexidade e a diversidade deste espaço de ensino (NOSELLA; BUFFA, 2008).

Para Oliveira e Gatti Jr. (2002), a renovação nas abordagens das pesquisas sobre instituições educativas, ao ultrapassar os limites da Historiografia Tradicional, conferem à histórias destes lugares "um sentido histórico no contexto social de sua época, bem como suas influências até os nossos dias" (OLIVEIRA; GATTI JR., 2002, p. 73).

Diversas vertentes podem ser exploradas na pesquisa sobre uma instituição escolar, tendo em vista o seu movimento de criação e instalação, a constituição do seu espaço físico, sua organização interna e administração, seu público, seu quadro docente, seus processos pedagógicos. Estas tendências possibilitam construir um retrato da escola com seus autores, organização, cotidiano, cultura e sua significação para determinada sociedade que a compõe (BUFFA, 2002).

Diante da multidimensionalidade de investigação contida nas instituições escolares e de ensino, os arquivos escolares são um dos componentes fundamentais para 0 desenvolvimento de estudos, sendo espaços que estão cada vez mais adquirindo maior atenção dos pesquisadores. Os arquivos escolares são espaços de memória em que possuem fontes relacionadas à trajetória do fazer e pensar pedagógico perante o cotidiano das escolas (BONATO, 2002).

Ao investigar as ações da sociedade humana ao longo do tempo, o pesquisador necessita de indícios produzidos pelo corpo social analisado. Dessa forma, os arquivos escolares oferecem acesso a uma diversidade de registros administrativos, pedagógicos e culturais relacionados ao movimento das instituições escolares e de seus sujeitos, fornecendo elementos sobre sua história, seu funcionamento, suas práticas e relações estabelecidas, abarcando também informações sobre a História Social dos seus agentes.

Documentos como prontuários dos alunos, livros de ponto, livros de matrícula, cadernetas escolares, fotografias, ofícios, atas, relatórios, livros de matrícula, material didático, diário de classe, históricos escolares, diário oficial, pasta de alunos e de professores são encontrados nos arquivos escolares, incorporando um contingente de possibilidades e objetos de estudo e pesquisa em História da Educação.

Mesmo com este arsenal de fontes fomentadoras do campo historiográfico educacional, muitas vezes estes espaços são percebidos pelos sujeitos que atuam nas escolas 
como um local de armazenamento de documentos de uso exclusivo do setor administrativo; "servem" para comprovar a vida escolar dos alunos e funcional dos professores e funcionários. A denominação "arquivo morto" ou "arquivo passivo" expressa essa ideia, ignorando sua função histórica e cultural.

A situação da maioria destes locais no Brasil é crítica, uma vez que eles não estão estruturados de modo adequado e seus documentos mantidos em péssimas condições de conversação e preservação, tornando-os suscetíveis a poeira, roedores, insetos, microorganismos. Tal situação ocasiona deterioração e, consequentemente, perdas para o campo investigativo/científico e para a História Local e Nacional.

\section{APRESENTAÇÃO DO PROJETO E SUBPROJETO}

O Projeto Levantamento de Fontes sobre a História do Ensino de História nos municípios do entorno do DCH-Campus VI, sob direção da professora Antonieta Miguel, investiga, levanta e cataloga as fontes referentes à Educação encontradas em arquivos, principalmente os escolares, dos municípios próximos ao Departamento de Ciências Humanas- Campus VI, Caetité-Bahia. Já executamos este processo de exame nas cidades de Rio de Contas, Macaúbas e na antiga DIREC de Caetité, tendo como próximos alvos Igaporã, Mucugê e Palmas de Monte Alto.

Como desdobramento, o subprojeto intitulado Colégio Estadual Governador Luiz Viana Filho: instituição, arquivo escolar e possibilidades de pesquisa (1956-1994) ${ }^{1}$, também sob orientação da professora Antonieta Miguel, objetiva inventariar a documentação referente à história desta instituição escolar (objeto desta pesquisa) e produzir um Catálogo de Fontes Primárias, apresentando a documentação investigada e elencando suas possíveis possibilidades de investigação histórica perante o objeto em estudo. Além disso, o Catálogo produzido abarca também conhecimentos teóricos sobre os Arquivos e as Instituições Escolares, assim como retrata a história do colégio, a situação que se encontra seu arquivo e seus documentos, apontando possíveis soluções em relação aos problemas de conservação e preservação destes espaços.

A escolha de realizar este estudo se deu pelo parco número de investigações na Bahia sobre a História das Instituições Escolares e seus Arquivos, apesar do crescimento considerável de pesquisas nessa direção. A ausência de instrumentos de suporte à pesquisa em

\footnotetext{
${ }^{1}$ Este subprojeto é financiado pelo PICIN/UNEB.
} 
arquivos e outros locais de mesma natureza foi o fator de escolha para a produção de um Catálogo de Fontes.

Algumas das instituições escolares mais antigas da Bahia foram objetos de estudo, inclusive em períodos diferentes, como o Liceu Provincial da Bahia, investigado através da tese As políticas públicas para o ensino secundário na Bahia: o Liceu Provincial - 1860-1890 (DICK, 2001) e em outro recorte temporal, na dissertação “O Banquete espiritual da instrução: o Ginásio da Bahia, Salvador: 1895-1942” (LIMA, 2003).

Outro importante trabalho, Escola Politécnica da Bahia: poder, política e educação na Bahia republicana (1896-1920) (BARBOSA, 2010), aborda a história dessa instituição de ensino "através de seus dirigentes, docentes e ex-alunos (que) alcançam destaque na sociedade civil e sociedade política, passando então a inscrever seus projetos de visão de mundo no interior da sociedade política." (2010, p. 17).

Para a região, alvo deste trabalho, o sudoeste baiano, as dissertações Anísio Teixeira e a Escola Normal de Caetité/BA: um projeto de formação de professores primários (1926/1941) (ROCHA, 2005) e Ginásio de Conquista - Memória de uma instituição escolar (1940-1960) (OLIVEIRA, 2009) são precursores de pesquisas acadêmicas que tomam as instituições escolares como objeto de investigação em programas de pós-graduação.

\section{Colégio Estadual Governador Luiz Viana Filho: origem e características}

O Colégio Estadual Governador Luiz Viana (CEGLVF) nasceu a partir da criação de duas instituições escolares: Ginásio de Guanambi e Ginásio São Lucas. O primeiro foi criado em 1953, na cidade de Guanambi, pelo médico e educador Dr. Laerte Ribeiro. Com a autorização do curso Pedagógico (Normal), em 1963, a instituição passou a ser chamada de Ginásio e Escola Normal de Guanambi, tendo caráter particular e filiada a determinado grupo político dono da Associação Amigos de Guanambi. Em seu período de existência, o ginásio possuiu quatro diretores e ofertou o ensino de $1^{\circ}$ grau e o curso Pedagógico, do primeiro ao terceiro ano.

Em 1958, é criado o Ginásio São Lucas, também pelo educador Dr. Laerte Ribeiro, junto com a professora Enedina Costa de Macedo. De caráter particular, esta instituição também sofreu alterações em seu nome com a criação do curso Normal, passando a ser intitulado como Ginásio e Escola Normal São Lucas. A instituição teve vários diretores e ela estava vinculada com a Associação Guanambiense de Cultura e Assistência Social, que era 
uma organização que também pertencia a determinado grupo político. Em certos documentos utilizados para a realização desta pesquisa, foi constatado que havia atritos entre os dois diferentes grupos políticos associados, cada um, a este Ginásio e ao Ginásio de Guanambi.

O surgimento do Colégio Estadual Governador Luiz Viana Filho se deu pela união entre as duas Associações mencionadas anteriormente, em que ambas doaram ao estado os prédios das instituições, junto aos seus equipamentos, sendo todo este processo guiado pelo Deputado Estadual Vilobaldo de Freitas e pelo prefeito de Guanambi Jonas Rodrigues da Silva. A instituição foi criada em cinco de fevereiro de 1970, por meio de decreto publicado no Diário Oficial e ela recebeu este nome como forma de homenagear o Dr. Luiz Viana Filho, governador do estado da Bahia, no período de 1967 a 1971, em que executou ações grandiosas em seu mandato, entre elas a criação do Instituto do Patrimônio Artístico e Cultural (IPAC) e ampliou a rede escolar do estado. O mesmo já esteve em Guanambi e fez uma visita ao colégio na década de 70 .

Inicialmente, a instituição possuía quarenta e cinco professores, cinco funcionários e aproximadamente noventa alunos do ensino fundamental e normal. Ela disponibilizou os cursos de Magistério, Administração, Técnico em Contabilidade, Agropecuária, Estudos Adicionais, Acadêmico e Exames Supletivos de $2^{\circ}$ grau. A Associação de Pais e Mestres APM, o Grêmio Cultural Estudantil Jorge Amado, que posteriormente se transformou em Centro Cívico Major Cosme de Farias, foram entidades que compuseram o colégio desde a década de 70. Atualmente, houve a ampliação do quadro docente, discente e de funcionários da instituição, sendo importante salientar que ainda se encontra um funcionário que trabalha na instituição desde quando esta era Ginásio de Guanambi. Hoje são ofertadas as modalidades de Ensino Médio ( $1^{\circ}$ ao $3^{\circ}$ ano) e Tempo Formativo - EJA III (nível fundamental e médio) na escola, não existindo mais o Ensino Fundamental na mesma.

\section{CONHECENDO OS LOCAIS QUE ACONDICIONAM A DOCUMENTAÇÃO DO CEGLVF}

\section{$O$ arquivo e o depósito do colégio, junto à situação de seus documentos}

O arquivo do Colégio Estadual Governador Luiz Viana Filho, lócus da pesquisa executada, está localizado ao lado do inativo Grêmio Estudantil, próximo à secretaria da escola. Ele possui um espaço específico para o seu funcionamento, composto pela 
documentação desta instituição, junto com a pertencente ao Colégio Normal de Guanambi e o Ginásio e Escola Normal São Lucas, além de materiais como banners, trabalhos de alunos e uma máquina de escrever.

Figura 1: arquivo do Colégio Estadual Governador Luiz Viana Filho, em Guanambi- Bahia.

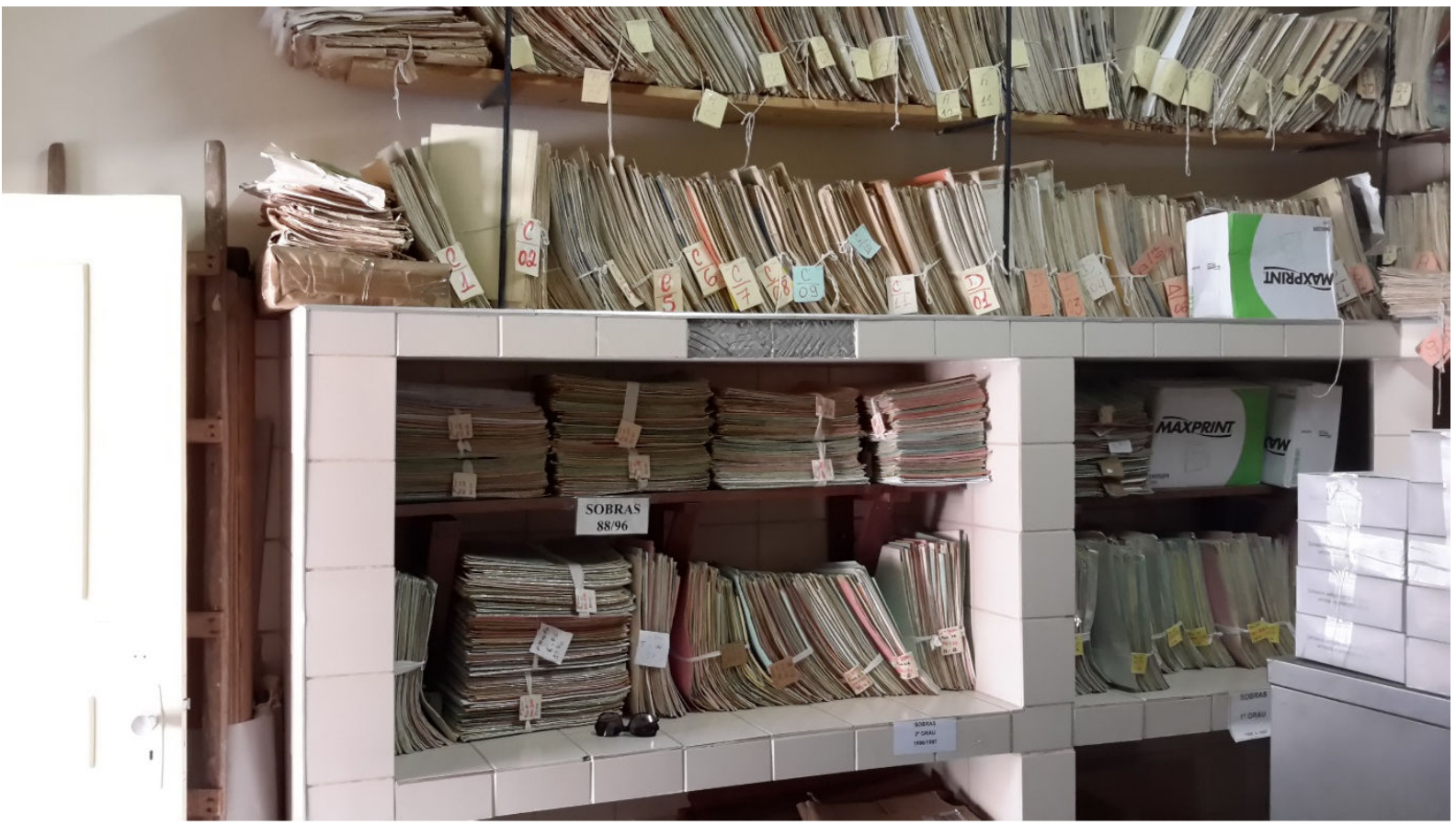

Fonte: Acervo do Laboratório de Pesquisa em Didática da História (LAPEDHI).

O local do arquivo é pequeno, totalmente fechado, sem janelas, o que facilita a concentração de poeira. Os documentos se encontram dentro de pastas em armário de ferro, outros amarrados com barbantes em cima de estantes de madeiras que estão prestes a desmoronarem, devido à grande quantidade de pastas que estão suportando. Outra parte dos documentos está em um armário de madeira e em prateleiras construídas com blocos e azulejos.

As documentações estão desorganizadas e empoeiradas, algumas amareladas, com tonalidades claras e/ou ilegíveis, muitas com grampos e clipes, com rasgões, coladas com fita adesiva ou esparadrapo, outras praticamente perdidas, muitas sem algum tipo de identificação (tipo e/ou data), todas elas sujeitas a insetos e sem ventilação adequada. Os materiais também se encontram empoeirados e sem nenhum tipo de proteção. 
Figura 2: documento encontrado rasgado e amassado, o que torna visível o mau estado de conservação e preservação do arquivo da instituição.

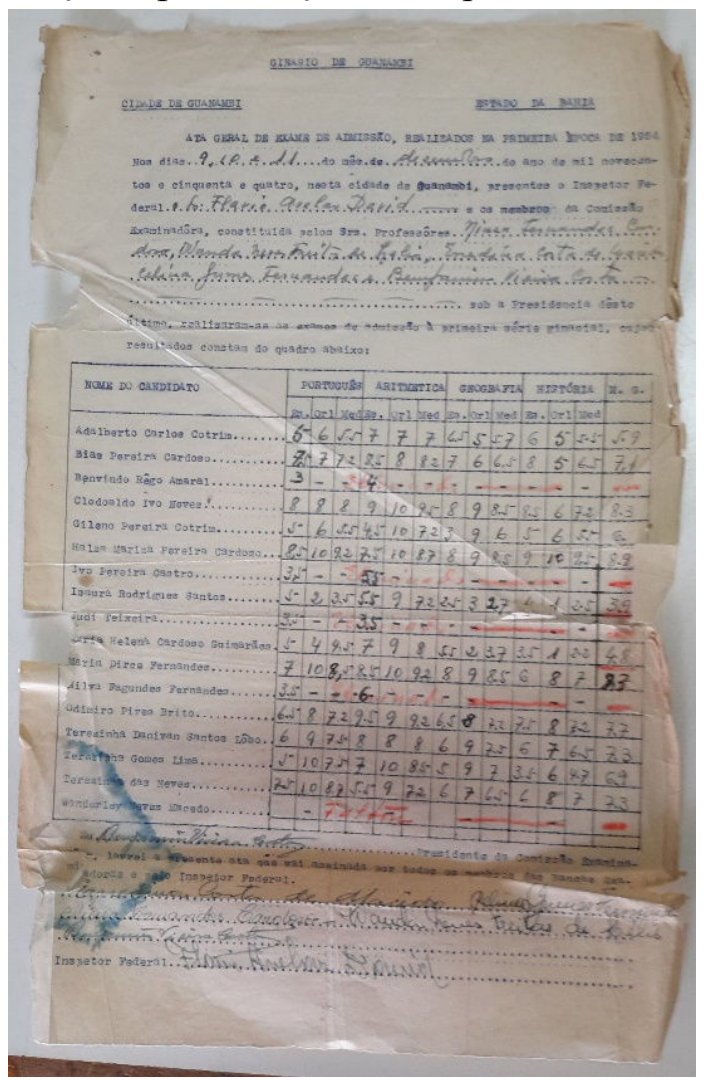

Fonte: Acervo do Laboratório de Pesquisa em Didática da História (LAPEDHI).

Figura 3: documentação manchada encontra no arquivo do Colégio Luiz Viana.

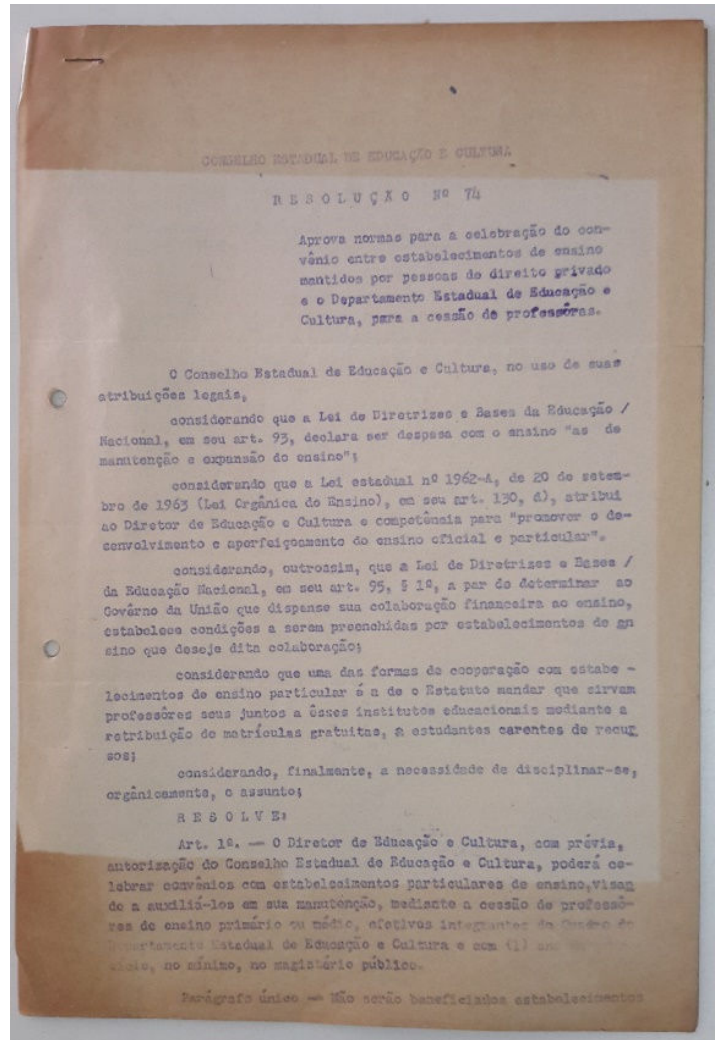

Fonte: Acervo do Laboratório de Pesquisa em Didática da História (LAPEDHI). 
Certos documentos do colégio foram incinerados nas décadas de 60 e 70, como consta em Livros de Incineração encontrados no arquivo da instituição relatando este ato. Este era executado com a presença de membros da escola, como professores, inspetor, diretores, funcionários e alunos, entretanto, estes livros não fazem referência ao método adotado pela escola para incinerar seus documentos, se eles utilizavam equipamentos próprios para este processo ou apenas os queimavam com a junção de álcool e fogo. Estes livros também não fazem referência ao motivo destas documentações terem sido incineradas e se elas, após serem eliminadas, foram registradas na "Lista de eliminação", além de não mencionarem se os documentos incinerados foram anteriormente analisados por profissionais desta área, junto aos indivíduos que compõem o educandário, consultando a tabela de temporariedade dos registros da escola e, consequentemente, se a incineração foi autorizada por autoridade competente e assinada pelas pessoas envolvidas neste ato.

Figura 4: Um dos Livros de Incineração encontrado no arquivo do Colégio Luiz Viana.

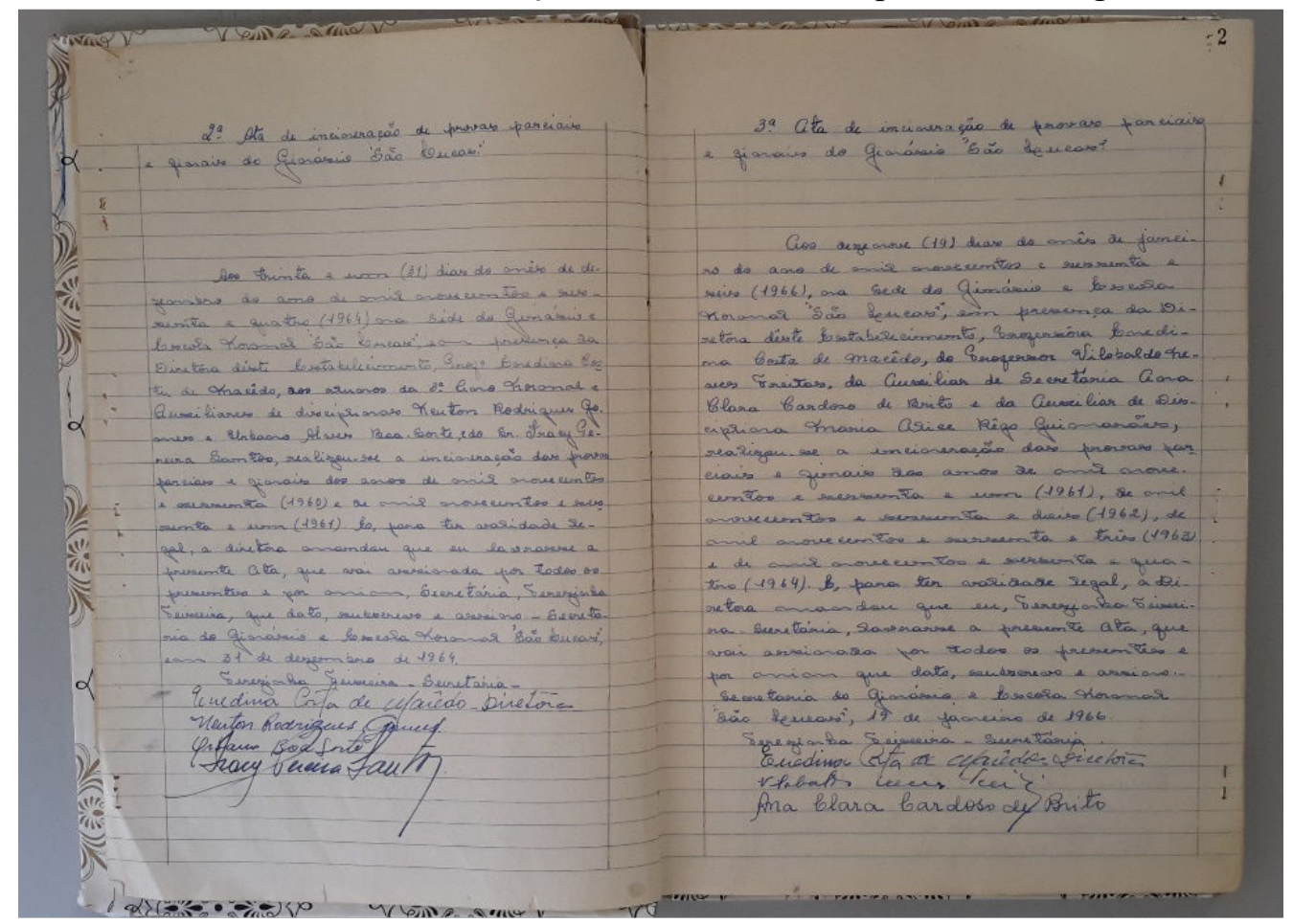

Fonte: Acervo do Laboratório de Pesquisa em Didática da História (LAPEDHI).

Em outras documentações encontradas neste espaço escolar, o Arquivo da instituição está limitado a guardar documentos como forma comprobatória e de verificação da vida escolar do estabelecimento, de cada aluno, a qualificação e atuação profisssional dos docentes e demais funcionários, ao movimento financeiro e econômico da instituição. 
É importante salientar que na fachada do arquivo está grafada a expressão “Arquivo passivo", o que lhe atribui a ideia de inatividade, ausência de movimentação neste espaço, sendo apenas um depósito de documentos vinculados à administração do colégio, à comprovação da dinâmica escolar de alunos, da rotina profissional de docentes e funcionários, contendo apenas visibilidade comprobatória, administrativa e burocrática, assim como está mencionado em alguns de seus documentos, ignorando a função dos arquivos como construtores da história, identidade e cidadania e sua visibilidade enquanto patrimônios da sociedade.

O colégio recebia de órgãos como a DIREC instruções relacionadas ao funcionamento dos arquivos. Os regimentos referentes à caracterização e a organização deste espaço escolar eram produzidos pelo próprio colégio, respeitando os preceitos encontrados em dispositivos da lei. Antes de entrem em vigor, os regimentos eram remetidos à Secretaria de Educação de Salvador para serem avaliados e, consequentemente, aprovados para uso.

$\mathrm{O}$ arquivo da instituição não possui profissionais especializados para lidar com os seus materiais. Os alunos do colégio desconhecem seu funcionamento e durante a realização desta pesquisa, fomos questionados sobre: "Qual a função deste arquivo?”, "Por que estes documentos estão guardados?" "Para que você está fazendo este trabalho?", o que torna evidente a invisibilidade discente perante este local.

Além do arquivo, o Colégio Estadual Governador Luiz Viana Filho acondiciona grande parte dos seus documentos em um depósito, localizado ao lado da cantina, no pátio da instituição. Este local possui três divisórias em que na primeira se encontram instrumentos musicais quebrados, armários com talheres e pratos utilizados para a merenda escolar, caixotes de madeira, mesa e sofás. Na segunda divisória estão diversos instrumentos musicais da fanfarra e várias latas de tinta empilhadas umas sobre as outras. Na terceira divisória se encontram os documentos da instituição, junto com materiais esportivos de Educação Física. Apenas a primeira divisória possui iluminação, estando as demais parcialmente escuras, devido a problemas apresentados em suas lâmpadas. 
Figura 5: Depósito do Colégio Luiz Viana contendo documentos da instituição.

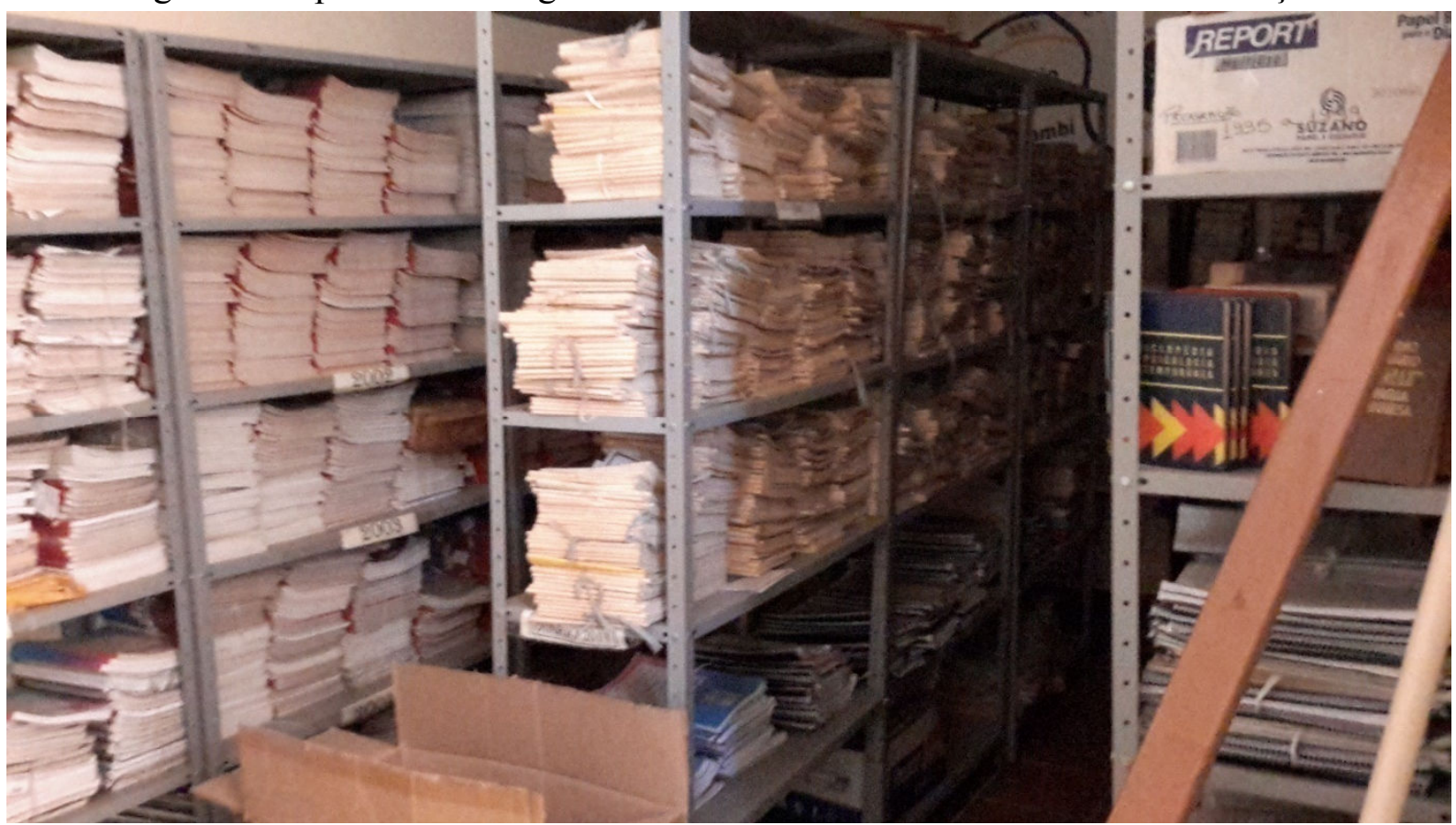

Fonte: Acervo do Laboratório de Pesquisa em Didática da História (LAPEDHI).

Neste depósito, os documentos estão todos sobre prateleiras de ferro, dentro de envelopes, pastas, classificadores, caixas de papelão, empilhados um em cima do outro, alguns amarrados com barbantes. A documentação, sendo vítimas do tempo e da ausência de conservação e preservação, se encontra bastante empoeirada, algumas partes estão com manchas amareladas, com dobras, rasgados, com tonalidade clara, sem nenhum tipo de proteção. Neste local, se encontram documentos a partir de 1970 até a documentação mais recente disponível, enquanto o Arquivo da instituição abarca registros desde a criação do Colégio e Escola Normal de Guanambi, em 1953, tendo também documentos mais recentes.

\section{As fontes que compõe o arquivo e o depósito do colégio}

Os arquivos escolares abarcam um contingente de fontes que podem ser utilizadas para a construção do conhecimento histórico. O arquivo do Luiz Viana pode ser caracterizado por sua multiplicidade de fontes. Neste espaço se encontram Ofícios, Correspondências e Telegramas expedidos e remetidos, Regimento escolar, Livros de matrícula, Livros de ponto de professores e funcionários, Diário Oficial, Pasta de alunos, de professores e funcionários da instituição, Livros de Atas e Livros de Incineração. As Pastas de Alunos são encontradas em maior número do que os demais documentos mencionados acima. 
No depósito do colégio estão as Correspondências, Ofícios, Planos de Trabalho, Atas, Relatórios de diversas atividades na escola, variados livros referentes à Psicologia, Matemática, História, Enciclopédias e os Diários de Classe que são os documentos escolares em maior número neste local em análise.

\section{SISTEMATIZAÇÃO DA PESQUISA E SEUS COMPONENTES}

\section{Pesquisa: o uso das fontes e a investigação em arquivos escolares}

O movimento humano que constrói a história deixa pistas, registros, indícios sobre suas ações no passado e no tempo presente. Tendo em vista esta concepção, as fontes escritas são um tipo de matéria-prima para o pesquisador investigar a dinâmica da sociedade ao longo do tempo, permitindo assim a construção do conhecimento histórico.

As descobertas científicas iniciadas no século XIX trouxeram transformações significativas em diversos setores, o que permitiu a mudança gradativa do modo de viver dos homens. A informação constitui-se um dos setores atingidos por estas mudanças de escala global, fazendo com que aumentasse efetivamente a sua produção, junto à elaboração de documentos, o que provocou o aumento de suportes teóricos e práticos a respeito dos meios de se lidar com esse grande número de documentos e informações.

Com uma nova tendência historiográfica configurada no século XX, novos olhares, objetos, ângulos de interpretação, novas metodologias, fontes, leituras, investigações foram inseridas no campo histórico-educativo, este se pluralizando, rompendo com limitações no campo do conhecimento. A história da educação abrange atualmente muitas históricas que se interligam e interagem mediante o objeto da educação, embora posto sob olhares diferentes em relação a sua fenomenologia (CAMBI, 1999).

No campo em estudo, a maioria dos seus objetos de pesquisa utiliza-se o uso de documentos para embasar e fundamentar seus estudos. Eles podem ser consultados em diversos lugares, como museus, bibliotecas, acervos, arquivos particulares, públicos e arquivos escolares. Este último possui uma multidimensionalidade de fontes e possibilidades de pesquisa. $\mathrm{O}$ arquivo está vinculado à vida da escola e pode disponibilizar elementos para a reflexão sobre o passado da instituição, dos indivíduos que estão passando ou passaram por lá, suas práticas e das relações estabelecidas na cidade e na região na qual está inserida (VIDAL, 2005). 
O pesquisador se depara com diversos registros nos arquivos, no entanto, para que eles sejam considerados como fontes, é necessário que tenham respostas para as indagações do pesquisador, para assim, junto ao seu olhar amplo, crítico e um arsenal teóricometodológico, as fontes sejam problematizadas e permitam a formação de novos discursos dentre as múltiplas interpretações contidas na produção do conhecimento histórico, tendo em vista a construção social contida deste tipo de estudo, ligando o particular ao universal e ultrapassando a sucessão narrativa-descritiva e linear dos fatos.

Há inúmeros empecilhos e dificuldades encontradas pelos pesquisadores de História da Educação, como a existência de documentos fora do acervo e do arquivo escolar, a dispersão e desorganização das fontes em lugares diferentes, a ausência de instrumentos de pesquisa para ajudar o profissional com o seu trabalho, questões burocráticas.

Ademais, a maioria dos arquivos escolares brasileiros está em situação crítica de organização, preservação e conservação dos seus espaços e seus componentes, dado que não possuem instalações adequadas, muitos não prescindem de ambiente disponível ao pesquisador, há ausência de profissionais específicos para lidar com seus materiais, que, muitas vezes, são manuseados de maneira inadequada, sofrem a ação de fatores biológicos e físicos, bem como carecem de recursos do poder público.

Frente a esta conjuntura problemática, é factível a existência de políticas públicas efetivas que visem à preservação e conservação de arquivos e que abranjam a sua visibilidade; realização do processo conjunto de organização, levantamento, catalogação, desinfestação, higienização dos documentos, evitando com que eles passem por processos mais radicais, como a restauração; incentivo à construção de instrumentos de pesquisa e a junção de arquivos com bibliotecas, acervos, museus e o diálogo entre seus profissionais com os educadores, pesquisadores, historiadores, buscando debater sobre a preservação e conservação destes espaços.

Outro aspecto importante seria utilizar pedagogicamente os documentos e o arquivo nas instituições escolares, como laboratórios, nas salas de aula, em exposições e projetos permanentes que permitam visualizar a função deste espaço escolar e seus elementos. Para isto, necessário envolver nesta perspectiva alunos, professores, outros indivíduos da escola e a população em geral com a finalidade de sensibilizá-los perante a situação da documentação escolar e fomentar sua consciência histórica, possibilitando assim desconstruir visões limitadas sobre os arquivos em geral e seus componentes e se reconhecerem enquanto agentes históricos. 


\section{Caminhos trilhados na realização da pesquisa}

A pesquisa científica executada constituiu-se em diversos caminhos para se chegar a sua conclusão. De modo abrangente, a produção do Catálogo de Fontes seguiu as etapas de planejamento e estudos teóricos, contato, análise e registro fotográfico do arquivo e sua documentação, produção escrita e, por último, parte gráfica.

Em primeiro momento, foram feitas leituras, discussões, elaboração de artigos, resenhas críticas, textos reflexivos a partir do levantamento bibliográfico incorporado ao campo da História da Educação e das Instituições escolares, abarcando arquivos, fontes, objetos, pesquisa científica e seus instrumentos de suporte, formas de ensino, educação, cultura escolar em livros, revistas, artigos, teses e dissertações, o que auxiliou na construção do conteúdo escrito do catálogo, na problematização das fontes e em outros pontos presentes na pesquisa.

Após este "contato teórico" com o objeto em estudo, partimos para as visitas ao Colégio Estadual Governador Luiz Viana Filho, dando início a parte mais fundamental, trabalhosa e minuciosa da pesquisa, examinando e levantando sua documentação, fazendo análises e questionamentos, escolhendo as fontes para compor o catálogo e registrando-as através de fotografias. Os documentos estavam completamente desorganizados, com sua tipologia e datas misturadas, o que tornou mais difícil a ordenação das fontes encontradas.

A catalogação dos documentos se deu a partir de fichas que construímos, contendo informações como item documental, sua data, autor, localização, estado que se encontra o documento, suas informações e as possibilidades de pesquisas que ele abrange. Realizamos este processo primeiro no Arquivo da instituição e, posteriormente, nos deslocamos para o depósito onde se encontrava outra parte da documentação da escola. Durante o processo de execução da pesquisa na instituição, as pessoas que trabalham nela foram educadas e prestativas, nos recepcionando de forma gentil, nos auxiliando quando era preciso. $\mathrm{O}$ funcionário mais velho da instituição, que exerce seu trabalho desde quando o educandário era Ginásio e Escola Normal de Guanambi, nos auxiliou em relação ao arquivo, o depósito e os seus componentes.

Considerando o contato bibliográfico obtido e as reflexões adquiridas a partir dele, se deu o processo de seleção das fontes a serem utilizadas no catálogo, classificando-as em temáticas. Posteriormente, se deu a catalogação dos documentos a partir de fichas digitais que construímos em um tablet, contendo informações como item documental, sua data, autor, 
localização, estado que se encontra o documento, suas informações e as possibilidades de pesquisas que ele abrange; começando, dessa forma, a construção do corpo escrito da pesquisa. É ideal ressaltar que este recurso digital que utilizamos nos ajudou bastante, proporcionando praticidade e economia de tempo no processo de execução da pesquisa.

Não somente os documentos do Colégio Luiz Viana foram importantes na realização do catalogo, a presença em seu arquivo e em outros espaços desta instituição escolar foram indispensáveis para a investigação e o aprofundamento do conteúdo do catálogo.

A etapa final (e mais delicada) da realização do catálogo foi seu processo gráfico operado em programas de computadores para edição gráfica (Corel Draw X7, Picasa 3 e PhotoScape). Tratamos as questões de iluminação e nitidez das fotografias no Picasa 3 e PhotoScape, sendo um processo rápido, já que as fotos foram tiradas por um equipamento portador de ótima qualidade de resolução. Após isso, se deu a montagem no catálogo no Corel Draw X7, de modo cuidadoso, gradativo e, depois que esta foi finalizada, realizamos sua impressão, possibilitando ser usado concretamente.

\section{O CATÁLOGO DE FONTES PRIMÁRIAS}

\section{Instrumentos de pesquisa e o Catálogo produzido}

A produção de uma pesquisa científica envolve coleta de materiais, estudo, investigações, criações, montagem e construção, sendo um trabalho árduo e que requer tempo. Como meio de facilitar o ofício dos pesquisadores, tem-se os instrumentos de pesquisa. Os arquivos brasileiros possuem déficit de presença destas ferramentas. Os instrumentos de pesquisa possuem composição vinculada a uma prática arquivista que tem como maior objetivo facilitar o acesso aos vestígios documentais (SANTANA, 2012).

Estes instrumentos permitem a localização, a consulta ou a identificação de documentos presentes neles. São eles: guias, inventários, índices, repertórios e catálogos. Possuindo uma ou mais temáticas, os catálogos reúnem diversas informações, facilitando o seu acesso, descrevem e divulgam as fontes, junto a sua disponibilidade no acervo apresentado e suas potencialidades, viabilizam objetos e possibilidades de pesquisas, impedem que estudos fiquem incompletos e promovem praticidade ao ofício do pesquisador na acessibilidade aos registros. 
O Catálogo de Fontes Primárias sobre o Colégio Estadual Governador Luiz Viana Filho é composto por uma apresentação inicial, falando sobre este instrumento e a pesquisa científica; uma introdução trazendo um conteúdo teórico a respeito da História da Educação, Instituição Escolar e Arquivos. Posteriormente, é apresentada a história do Colégio, abordando como se deu sua criação, sua composição e características iniciais, alcançando o tempo presente. Logo após, é exibido o Arquivo da instituição e do seu depósito, trazendo suas respectivas características. Mantendo sequência, tem-se a apresentação das fontes pesquisadas, divididas em diversas temáticas, envolvendo professores, Centro Cívico, o arquivo, entre outros pontos presentes na instituição. Nesta parte, é exibido as fotografias das fontes, seus tipos, seus anos, as informações que abarcam (visando a sua temática) e suas possibilidades de pesquisa dentro do objeto da História da Educação. Estas fontes viabilizam a análise e a exploração sobre a formação dessa instituição, seu cotidiano, sua cultura e relações estabelecidas na sociedade, realizar estudos sobre a formação de docentes, pedagogias aplicadas, postura dos discentes, dentre outras alternativas.

Após a exposição das fontes, tem-se uma abordagem sobre os Problemas de Conservação encontrados nos registros da escola, trazendo informações sobre a localização e a situação que se encontra os documentos da instituição, elencando os principais problemas que a maioria dos arquivos brasileiros são vítimas, assim como levanta possíveis soluções para este contexto. Por fim, tem-se as Considerações Finais sobre todo o trabalho produzido.

Anteriormente, produzimos também outro Catálogo, intitulado como Catálogo de Fontes Primárias: possibilidades de pesquisas em História da Educação no interior da Bahia: o Centro Educacional de Pindai (1975-1985), em que trouxemos informações sobre o arquivo desta instituição escolar, apresentamos a análise das suas fontes, classificadas em Correspondências, Currículos, Livros Didáticos, Cadernetas Escolares, Documentos Aleatórios, Livros diversos (livros de abertura do colégio, livros de matrícula, livros de ponto de professores), Atas, Diário Oficial, Pagamentos de mensalidades, abordando também os Problemas de Conservação da documentação encontrada e a crítica Arquitetura que se encontrava este educandário.

Ambas as ferramentas de pesquisa produzidas objetivam, de modo geral, atribuírem visibilidade às instituições escolares e seus arquivos e suas documentações, trazendo à vista todo o valor representativo, social, histórico e cultural que estes itens em conjunto possuem, a fim de fomentar consciência e criticidade histórica para a população em geral. O Catálogo produzido pode ser aplicado em futuras pesquisas científicas de pós-graduação, análises, 
produção de materiais didáticos, podendo também ser utilizado na própria escola e em outros ambientes que visem a preservação da memória histórica e educacional, dentro outras aplicabilidades. É ideal ressaltar que o instrumento construído não deve se restringir apenas para o público científico, estando disponível também ao público geral, inclusive para a comunidade escolar para que se conheça sobre o objeto abordado, a pesquisa e para desenvolver uma visão histórica e patrimonial dos arquivos e do acervo que o constitui.

\section{CONCLUSÕES}

O estado crítico dos arquivos escolares no Brasil e o desinteresse pela sua preservação e pela compreensão do uso de seus documentos é um dos fatores que preocupam os pesquisadores e educadores da atualidade. Hoje, a sociedade possui uma ótica errônea das instituições escolares, em que elas somente possuem a função de preparar os seus alunos para o mercado de trabalho, o que torna invisível sua constituição enquanto um espaço de memória educacional coletiva, que possui uma história e que possibilita também formar conhecimento histórico, como um elemento ligado à cultura e cidadania.

O Colégio Governador Luiz Viana Filho e seu arquivo escolar possuem uma significante potencialidade de riqueza social, histórica e cultural, o que ultrapassa o plano restrito da existência de seus documentos apenas para comprovação da administração e burocracia escolar, eclodindo na construção histórica e cultural. Mesmo com os problemas presentes em seu arquivo escolar, este colégio contém importantes documentos sobre a educação da cidade de Guanambi e sobre outros aspectos da sociedade, o que emerge uma pluralidade de viabilidades e objetos de pesquisa. Nesta perspectiva, os arquivos possuem alta potencialidade e são fundamentais para a construção do conhecimento histórico, das memórias, da identidade, autonomia e cidadania, constituindo como patrimônio histórico e cultural, formadores de identidade e cidadania, não sendo lugares inertes e invisíveis, necessitando de condições eficientes de tratamento, conservação e preservação.

Consideramos importante que a memória educacional presente nos arquivos e em outros ambientes se insira no ângulo construtivo de um melhor futuro pedagógico/didático, ampliando os horizontes educacionais a partir do diálogo com o passado e que, junto a isso, permita a construção do indivíduo como ser autônomo, articulado, pensante, na compreensão de si mesmo e com posicionamento crítico no espaço em que está inserido, promovendo a sua melhoria. 


\section{REFERÊNCIAS}

BARBOSA, Emiliano Côrtes. Escola Politécnica da Bahia: poder, política e educação na Bahia republicana. 2010. 272 f. Dissertação (Mestrado em História Social) - Universidade Federal Fluminense, Niterói.

BONATO, Nailda Marinho da Costa. Arquivos escolares: limites e possibilidades para a pesquisa. In: REUNIÃO ANUAL DA ANPED. Educação: manifestos, lutas e utopias. Anais... $\quad$ Caxambu, 25, $2002 . \quad$ Disponível em: $<$ http://25reuniao.anped.org.br/excedentes25/naildamarinhocostabonatot02.rtf $>$. Acesso em: 25 fev. 2016.

BUFFA, Ester. História e filosofia das instituições escolares. In: ARAÚJO, José Carlos Souza; GATTI JUNIOR, Décio (Org.). Novos temas em história da educação brasileira: instituições escolares e educação na imprensa. Campinas/SP: Autores Associados; Uberlândia: EDUFU, 2002. 226p.

CAMBI, Franco. História da Pedagogia. Trad. Álvaro Lorencini. São Paulo: Editora da UNESP, 1999. 700p.

DICK, Sara Martha. As políticas públicas para o ensino secundário na Bahia: o Liceu Provincial: 1860-1890. 2001. 280 f. Tese (Doutorado) - Universidade Federal da Bahia, Salvador.

LIMA, Déborah Kelman de. "O banquete espiritual da instrução"- O Ginásio da Bahia, Salvador: 1895-1942. 2003. 174 f. Dissertação (Mestrado em História) - Universidade Federal da Bahia, Salvador.

OLIVEIRA, Edileusa Santos. O Ginásio de Conquista: memória de uma instituição escolar (1940-1960). 2009. 211 f. Dissertação (Mestrado em História: Linguagem e Sociedade) Universidade Estadual do Sudoeste da Bahia, Vitória da Conquista.

OLIVEIRA, Lúcia Helena M. M.; GATTI JÚNIOR, Décio. História das Instituições Educativas: um novo olhar historiográfico. Cadernos de História da Educação, 1, jan./dez. 2002. Disponível em: <http://www.seer.ufu.br/index.php/che/article/view/310/302>. Acesso em: 07 nov. 2016.

NOSELLA, Paolo; BUFFA, Ester. Instituições escolares: por que e como pesquisar. In: SANTOS, Ademir Valdir dos; VECHIA, Ariclê. (Org.). Cultura Escolar e História das Práticas Pedagógicas. Curitiba: UTP, 2008. 162p.

ROCHA, Adriana de Oliveira. Anísio Teixeira e a Escola Normal de Caetité/BA: um projeto de formação de professores primários (1926/1941). 2005. Dissertação (Mestrado) Universidade Federal de Santa Catarina, Florianópolis. 
SANTANA, Sayonara Rodrigues do Nascimento. Por entre as memórias de uma instituição: o arquivo e as práticas administrativas do Atheneu Sergipense (1870-1926). São Cristóvão, SE: 2012. Dissertação (Mestrado) - Programa de Pós Graduação em Educação, Universidade Federal de Sergipe. Disponível em: $<$ https://bdtd.ufs.br/bitstream/tede/1789/1/SAYONARA_RODRIGUES_NASCIMENTO_SA NTANA.pdf $>$. Acesso em: 03 fev. 2016.

VIDAL, Diana Gonçalves. Cultura e prática escolares: uma reflexão sobre documentos e arquivos escolares. In: SOUZA, Rosa Fátima; VALDEMARIN, Vera Teresa (Org.). A cultura escolar em debate: questões conceituais, metodológicas e desafios para a pesquisa. Campinas: Autores Associados, 2005. 208p. 